\title{
Mezial temporal lob epilepsisi tanısı alan hastalarda lateralizasyonun bellek ve yürütücü işlevler üzerine etkisi
}

\author{
Lateralization effect on memory and executive functions in mesial temporal lobe epilepsy
}

Burcu Yüksel, Sibel Çeliker Uslu

Gönderilme tarihi:28.09.2018

Kabul tarihi: 01.02.2019

\section{Özet}

Amaç: Çalışmamızda sağ ya da sol hipokampal sklerozu (HS) olup mezial temporal lob epilepsisi (MTLE) tanısı alan hastaların bellek ve frontal lob fonksiyonlarını karşılaştırarak, bu fonksiyonların hastalık lateralizasyonu ile ilişkisini araştırmayı amaçladık.

Gereç ve Yöntem: Hastalar 2017 ILAE Revize Nöbet Sınıflamasına göre sınıflandırıldı. Mezial temporal lob epilepsisi tanısı almış olan 79 MTLE-HS hastası ve 30 benzer yaş, cinsiyet ve eğitim durumuna sahip sağlıklı kontrol çalışmaya dahil edildi. Çalışmamızda sağ ve sol HS'u olan hastalar, bellek ve frontal lob fonksiyonları yönünden karşılaştırıldı. Hafıza ve yürütücü işlevler testleri tüm katılımcılara uygulandı.

Bulgular: MTLE-HS tanısı alan hastaların 49'u (\%62) kadın ve 30'u (\%38) erkekti.

Bulgular: MMTLE-HS tanısı alan hastaların 49'u (\%62) kadın ve 30'u (\%38) erkekti. Kontrol grubu 14 $(\% 46,7)$ kadın ve $16(\% 53,3)$ erkekten oluşmaktaydı. Hastaların ve kontrol grubunun ortalama yaşları sırasıyla;

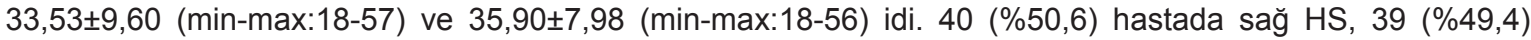
hastada sol HS saptanmıştı. Hem sağ hem de sol HS'lu hastaların bellek, dikkat ve diğer frontal lob fonksiyonları kontrol grubuna göre anlamlı derecede başarısızdı $(p<0,05)$. Sol HS'lu hastaların SBST'de en fazla temsil edici alt test olan geri çağırma skoru, sağ HS'lu hastalara göre anlamlı düzeyde düşük bulundu $(p=0,001)$. Sol HS'u olan olguların SBST tanıma sayıları hastalık lateralizasyonu sağ taraf olan olgulara göre istatistiksel olarak anlamlı düzeyde yüksekti $(p=0,001)$. Görsel bellek açısından değerlendirdiğimizde ise sağ ve sol HS'u olan hastalar arasında görsel bellek performansları açısından anlamlı fark bulunmadı $(p>0,05)$. Sağ ve sol HS'u olan hastalarda dikkat ve diğer frontal lob fonksiyonları açısından anlamlı fark saptanmadı $(p>0,05)$.

Sonuç: Sol HS'lu hastalarda sözel bellek testlerinden geri çağırma skorunu, sağ HS'lu hastalara göre anlamlı düzeyde düşük bulmamız sözel bellek bozukluğunun sola lateralize edilebileceğini ancak görsel bellek açısından fark bulmamamız literatürdeki çelişkili sonuçlara benzer şekilde bu fonksiyonun her zaman sağa lateralize edilemeyeceğini doğrulamıştır. Dikkat ve diğer yürütücü işlev performansları açısından anlamlı fark bulmamamız ise dikkat ve diğer yürütücü işlevlerde bozulmanın hastalık lateralizasyonu ile ilişkisi olmadığını düşündürtmüştür.

Anahtar Kelimeler: Mezial temporal lob epilepsisi, hipokampal skleroz, bellek.

Yüksel B, Çeliker Uslu S. Mezial temporal lob epilepsisi tanısı alan hastalarda lateralizasyonun bellek ve yürütücü işlevler üzerine etkisi. Pam Tıp Derg 2019;12:289-296.

\footnotetext{
Abstract

Purpose: The patients who were diagnosed with mesial temporal lobe epilepsy (MTLE) were included to the study. The aim of this study was to compare patients with right or left hippocampal sclerosis (HS) among memory and executive functions and to search if there is lateralization effect on these functions.

Materials and Methods:Patients were classified according to 2017 ILAE Classification of Seizures criteria. 79 patients with MTLE-HS and 30 healthy controls with similar age, sex and education degrees were enrolled in the study. The patients with right or left HS were compared in terms of memory and executive functions. Tests evaluating memory and executive functions were performed to all participants.

Results:Forty-nine (62\%) female and $30(38 \%)$ male patients with MTLE-HS, and $14(46.7 \%)$ female and 16 $(53.3 \%)$ male controls participated in the study. The mean age of the patients and controls was $33.53 \pm 9.60$ (range, 18-57) years and 35.90 \pm 7.98 (range, 18-56) years, respectively. 40 (50.6\%) patients had right HS and $39(49.4 \%)$ had left HS. When comparing patients with controls, scores of tests evaluating memory, attention and other executive functions were found significantly lower in patients than controls $(p<0.05)$. Recall score of Verbal Memory-Recall, Recognition, Total Learning-Tests (VMT) was significantly lower while recognition scores were higher in left HS patients than right HS patients $(p=0.001)$. There were no significant differences between right and left HS patients concerning visual memory scores or executive functions $(p>0.05)$.

Conclusion: In our study, the lower recall scores of VMT in left HS suggested us that deficits in verbal memory tests could be lateralized to the left, however finding no difference in visual memory function would not always

Burcu Yüksel, Uz.Dr, Sağlık Bilimleri Üniversitesi Antalya Eğitim ve Araştırma Hastanesi Nöroloji Kliniği, ANTALYA, e-posta: dr.burcuy@hotmail. com, (orcid.org/0000-0003-3976-5564) (Sorumlu yazar).

Sibel Çeliker Uslu, Uz.Dr, Sağlık Bilimleri Üniversitesi Samsun Eğitim ve Araştırma Hastanesi Nöroloji Kliniği, SAMSUN, e-posta: celikersibel@ hotmail.com (orcid.org/0000-0002-9035-7972)
} 
be lateralized to the right similar to conflicting results in the literature. There were no significant differences between right and left HS concerning attention and other executive functions. Thus, we suggested that defisits in these functions would not help us to lateralize the disorder.

Key Words: Mesial temporal lobe epilepsy, hipocampal sclerosis, memory.

Yüksel B, Çeliker Uslu S. Lateralization effect on memory and executive functions in mesial temporal lobe epilepsy. Pam Med J 2019;12:289-296.

\section{Giriş}

Meziyal temporal lob epilepsili hastalarda bellek fonksiyonundaki bozulmanın hipokampal patolojiden dolayı ilişkisi daha net bilinmesine rağmen, dikkat ve frontal lob fonksiyonunda da bozulma görülebilmektedir. Epilepsi hastalarında dikkat, mental işlemleme hızı, öğrenme ve bellek, yürütücü işlevler gibi çeşitli mental alanların birinde veya birkaçında birden bozulmalar olabilir [1].

Kognitif fonksiyon bozukluğu olarak en sık karşımıza bellek bozukluğu çıkmakta olup, bu bozukluğa en sık temporal lob epilepsisinde (TLE) rastlanır. TLE'li çok sayıda olguda belleğin yanı sıra dil, yürütücü işlevler ve motor hız alanlarında kötüleşme gösterilmiştir [2]. Temporal lob epilepsisi olan hastalar arasında ise MTLE'li hastaların bellek fonksiyonlarının diğerlerine göre daha fazla etkilendiği düşünülmektedir. MTLE sendromu olan hastalarda en sık rastlanan etyolojik neden \%60-70 oranı ile HS'dur [3, 4]. MTLE'li hastalarda temel nöropsikolojik bozukluk materyale özgü bellek bozukluklarıdır. İlk olarak Milner ve ark.'nın çalışmalarıyla ortaya konulan bu kavram, temelde sağ ve sol temporal lobların farklı tipteki bellek materyalini işlemesi olarak tarif edilir [5, 6]. Sözel bellek sol hemisfer, görsel bellek sağ hemisfer ile ilişkilendirilir. Bu kurama göre insan belleğinde; sözel ve görsel materyalin ayrı ayrı işlemlenmesinde (materyale özgü) sağ ve sol temporal loblar birbirini bütünler [7]. MTLE'de 'uzun süreli bellek' (yeni öğrenilmiş bilginin geri çağırılması) bozukluğu tipiktir. Tutulan hemisferin dil dominansına göre hafiforta dereceli materyale özgü bellek bozukluğu da bulunur. Eğer sol hemisfer dominantsa, sözel bellek bozukluğu sol hemisferi lateralize edebilir. Buna karşın görsel bellek bozukluğu ile sağ temporal lob arasında ilişki kurmak güç olmaktadır [8].
Biz de çalışmamızda sağ ve sol HS'lu hastalarda bellek ve frontal lob fonksiyonlarının hastalık lateralizasyonu ile ilişkisini araştırdık. Ayrıca sağ veya sol HS'lu hastaları kontrol grubuyla karşılaştırarak hem sözel hem de görsel bellekte, dikkat ve diğer yürütücü işlevlerde bir etkilenme olup olmayacağını saptamaya çalıştık.

\section{Gereç ve yöntem}

Hastalar 2017 ILAE Revize Nöbet Sınıflamasına göre sınıflandırıldı. Mezial temporal lob epilepsisi tanısı almış olan 79 hasta ve 30 benzer yaş, cinsiyet ve eğitim durumuna sahip sağlıklı kontrol çalışmaya dahil edildi. Çalışmamızda sağ ve sol HS'u olan hastalar, bellek ve frontal lob fonksiyonları yönünden karşılaştıııldı. Hasta ve kontrol gruplarında, belleği değerlendirmek için Sözel Bellek Süreçleri (SBST), Mantıksal Bellek Testi ve Wechsler Memory Scale (WMS) Görsel Bellek Testi kullanıldı. Frontal lob fonksiyonlarından dikkati değerlendirmek için hastalara Digit Span testi, diğer yürütücü işlevleri değerlendirmek için Stroop testi, verbal akıcılık testi, ardışık kategori adlandırma testi uygulandı. Kognitif durumda etkilenmeye yol açabilecek depresyon, sistemik hastalık, ilaç veya madde kullanımı olmayan, son bir hafta içinde nöbet geçirmemiş olan hastalar çalışmaya alındı. MTLE-HS nedeniyle opere olmuş olanlar, kraniyal magnetik rezonans görüntülemede (MRG) veya elektroensefalografide (EEG) bilateral etkilenimi saptanan veya başka serebral lezyonu bulunanlar ve mental retardasyonu olanlar dışlandı. Hastaların demografik ve klinik bilgileri (yaş, cinsiyet, eğitim düzeyi, epilepsi başlangıç yaşı, hastalık süresi, febril konvülsiyon (FK) öyküsü, ailede epilepsi öyküsü, anne-baba arası akrabalık, nöbet tipi, kullandığı antiepileptik ilaçlar (AEI) kaydedildi (Tablo 1). İstatistiksel analizler için NCSS (Number Cruncher Statistical System) 2007\&PASS (Power Analysis and Sample Size) 2008 Statistical Software (NCSS LLC, Kaysville, Utah, USA) programı kullanıldı. 
Çalışma verileri değerlendirilirken tanımlayıcı istatistiksel metodların yanı sıra iki gruba göre karşılaştırmalarda Student $t$ test kullanıldı. Normal dağılım göstermeyen değişkenlerin gruplar arası karşılaştırmalarında Kruskal Wallis test ve farklılığa neden çıkan grubun tespitinde
Mann Whitney $U$ test kullanıldı. Niteliksel verilerin karşılaştırılmasında ise Pearson KiKare testi, Yates Continuity Correction ve Fisher Freeman Halton test kullanıldı. Sonuçlar \%95'lik güven aralığında, anlamlılık $p<0,05$ düzeyinde değerlendirildi.

Tablo 1. Hastalığa ilişkin özelliklerin dağılımı.

\begin{tabular}{|c|c|c|c|}
\hline & & Min-Max & OrttSD \\
\hline \multicolumn{2}{|c|}{ Nöbet Başlangıç Yaşı (n=79) } & $1-45$ & $15,17 \pm 10,17$ \\
\hline \multirow{2}{*}{\multicolumn{2}{|c|}{ Hastalık Süresi (n=79) }} & $2-42$ & $18,96 \pm 8,58$ \\
\hline & & $\mathbf{N}$ & $\%$ \\
\hline \multirow{2}{*}{ Lokalizasyon } & Sağ & 40 & 36,7 \\
\hline & Sol & 39 & 35,8 \\
\hline \multirow{2}{*}{ İlaca yanıt } & İyi yanıtlı & 34 & 31,2 \\
\hline & Dirençli & 45 & 41,3 \\
\hline \multicolumn{2}{|c|}{ Febril Konvulsiyon Öyküsü (n=79) } & 49 & 62,0 \\
\hline \multicolumn{2}{|c|}{ Ailede Epilepsi Öyküsü (n=79) } & 14 & 17,7 \\
\hline \multicolumn{2}{|c|}{ Anne - Baba Arası Akrabalık $(n=79)$} & 16 & 20,3 \\
\hline \multirow{2}{*}{ Terapi $(n=79)$} & Monoterapi & 19 & 24 \\
\hline & Politerapi & 60 & 76 \\
\hline
\end{tabular}

\section{Bulgular}

Çalışmaya katılan tüm hastalar sağ elliydi. MTLE-HS tanısı alan hastaların 49'u (\%62) kadın ve 30'u (\%38) erkekti. Kontrol grubu $14(\% 46,7)$ kadın ve $16(\% 53,3)$ erkekten oluşmaktaydı. Hastaların ve kontrol grubunun

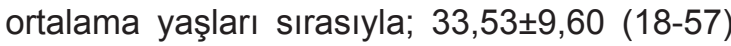
ve $35,90 \pm 7,98(18-56)$ idi. 40 hastada $(\% 50,6)$ sağ HS, 39 hastada $(\% 49,4)$ sol HS saptanmıştı. Hem sağ hem de sol HS'lu hastaların bellek, dikkat ve diğer frontal lob fonksiyonları kontrol grubuna göre anlamlı derecede başarısızdı $(p<0,05)$. Sol HS'lu hastaların SBST'de en fazla temsil edici alt test olan geri çağırma skoru, sağ HS'lu hastalara göre anlamlı düzeyde düşük bulundu $(p=0,001)$. Sol HS'u olan olguların SBST tanıma sayıları hastalık lateralizasyonu sağ taraf olan olgulara göre istatistiksel olarak anlamlı düzeyde yüksekti $(p=0,001)$. Sol HS'u olan olguların SBST öğrenme testinden aldıkları toplam puanlar, sağ HS'u olan olgulara göre istatistiksel olarak anlamlı düzeyde düşüktü $(p<0,05)$. Görsel bellek açısından değerlendirdiğimizde ise sağ ve sol HS'u olan hastalar arasında görsel bellek performansları açısından anlamlı fark bulunmadı $(p>0,05)$. Sağ ve sol HS'u olan hastalar arasında mantıksal bellek performansları açısından da fark yoktu $(p>0,05)$. Sağ ve sol HS'u olan hastalarda dikkat ve diğer frontal lob fonksiyonları açısından anlamlı fark saptanmadı $(p>0,05)$ (Tablo 2).

\section{Tartışma}

Çalışmamızda, sağ ve sol HS'u olan hastalar, sözel belleğin tüm alt testlerinde ve görsel bellek testlerinde kontrol grubuna göre istatistiksel olarak anlamlı düşük performans göstermiştir. Sağ ve sol HS'u olan hastaları materyale özgü bellek bozukluğu açısından karşılaştırdığımızda; sol HS'u olan hastaların sözel bellek için en fazla temsil edici alt test olan geri çağırma skorunu, sağ HS'u olan hastalara göre anlamlı düzeyde düşük bulduk. Görsel bellek açısından değerlendirdiğimizde ise sağ ve sol MTLE hastaları arasında görsel bellek performansları açısından anlamlı fark bulmadık. Taraf ile uyumlu materyale özgü bellek bozukluğunu sol HS'u olan hastalarda saptamışken, sağ HS'u olan hastalarda saptamadık. Bu bulgular bu alanda yapılmış birçok çalışma ile uyumludur. Birçok çalışmada MTLE-HS hastalarında altta yatan patoloji ile nöropsikolojik değerlendirme arasındaki ilişkinin incelenmesi amaçlanmıştır. 
Tablo 2. Hastalık lateralizasyonuna göre test sonuçlarının değerlendirilmesi.

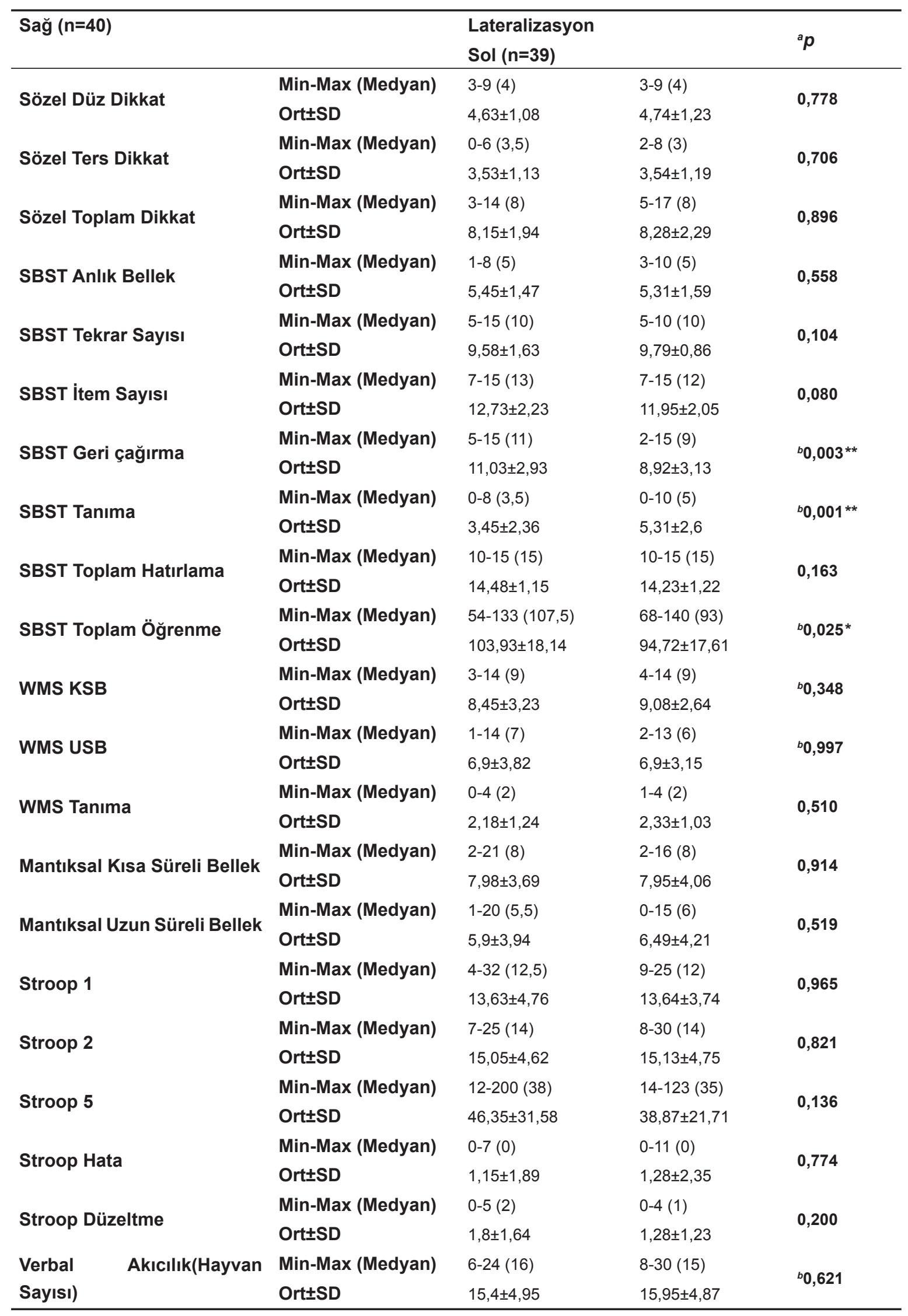


Tablo 2. Hastalık lateralizasyonuna göre test sonuçlarının değerlendirilmesi. (devamı)

\begin{tabular}{|c|c|c|c|c|}
\hline \multirow{2}{*}{$\begin{array}{l}\text { Verbal Akıcılık(Hayvan } \\
\text { Perseverasyon) }\end{array}$} & Min-Max (Medyan) & $0-3(0)$ & $0-2(0)$ & \multirow{2}{*}{0,325} \\
\hline & Ort $\pm S D$ & $0,4 \pm 0,74$ & $0,26 \pm 0,59$ & \\
\hline \multirow{2}{*}{$\begin{array}{l}\text { Ardışık Kategori Adlandırma } \\
\text { Testi (M/I sayısı) }\end{array}$} & Min-Max (Medyan) & $4-11(7,00)$ & $3-11(6,00)$ & \multirow{2}{*}{${ }^{b} 0,068$} \\
\hline & Ort $\pm S D$ & $7,15 \pm 1,76$ & $6,38 \pm 1,91$ & \\
\hline \multirow{2}{*}{ M/I (Perseverasyon) } & Min-Max (Medyan) & $0-6(0,00)$ & $0-3(0,00)$ & \multirow{2}{*}{0,732} \\
\hline & Ort $\pm S D$ & $0,60 \pm 1,03$ & $0,72 \pm 0,99$ & \\
\hline \multirow[b]{2}{*}{ M/I Kategori Değiştirememe } & Min-Max (Medyan) & $0-1(0,00)$ & $0-3(0,00)$ & \multirow[b]{2}{*}{0,932} \\
\hline & OrttSD & $0.13+0.33$ & $018+056$ & \\
\hline
\end{tabular}

aMann Whitney U Test ${ }^{b}$ Student-t Test $\quad{ }^{*} p<0,05 \quad{ }^{* *} p<0,01$

Bu çalışmalar sonucunda sol HS derecesi ile sözel bellek kaybı arasında bir korelasyon olduğu görülmüş, ancak aynı ilişki sağ HS ve görsel bellek kaybı arasında saptanamamıştır [9-11]. Wagner ve ark. tarafından 96 unilateral HS'u olan hasta grubunda yapılan bir çalışmada, sol HS'u olan hastalarda sözel bellek testlerinde ciddi düzeyde bozulma saptanmış, görsel bellek testlerinde ise sağ HS'u olanlarla ve kontrol grubu ile karşılaştııılığında anlamlı bozulma saptanmamıştır [12]. GlikmannJohnston ve ark. sağ ve sol HS'lu hastalarda görsel bellek testlerinde lateralize edici bir farklılık saptamamışlar, test sonuçlarını da hastaların hipokampal asimetri skorlarıyla ilişkili bulmamışlardır. Bu nedenle, görsel belleğin sağ ve sol mesial temporal lobda sistematik olarak iki yanlı entegre edildiği, materyale özgü bir özellik göstermediği sonucuna varmışlardır. Materyale özgünlük teorisi çerçevesinde sözel ve görsel belleğin tümüyle sağ veya sol temporal lobda lateralize olmadığı, bu bakışın modifikasyona intiyacı olduğunu ileri sürmüşlerdir [13]. Aynı şekilde Hanoğlu ve arkadaşları 137 MTLE hastasını materyale özgü bellek bozukluğu açısından değerlendirmişlerdir. Sol HS'u olan hastaların \%44,6'sı, sağ HS'u olan hastaların ise $\% 5,5$ 'i materyale özgü bellek bozukluğu göstermiştir. Ayrıca hem sözel, hem de görsel belleğin etkilendiği, global bir etkilenme de oldukça sık izlenmiştir (sol HS'da \%21,4 ve sağ HS'da \%17,8). Sağ HS'u olan hastalarda ise yüksek oranda sözel bellek bozukluğu saptamışlardır (\%26). Sağ HS'u olan hastalarda karşı tarafa ait materyale özgü bellekte düşük performans izlenmesi nedeniyle materyale

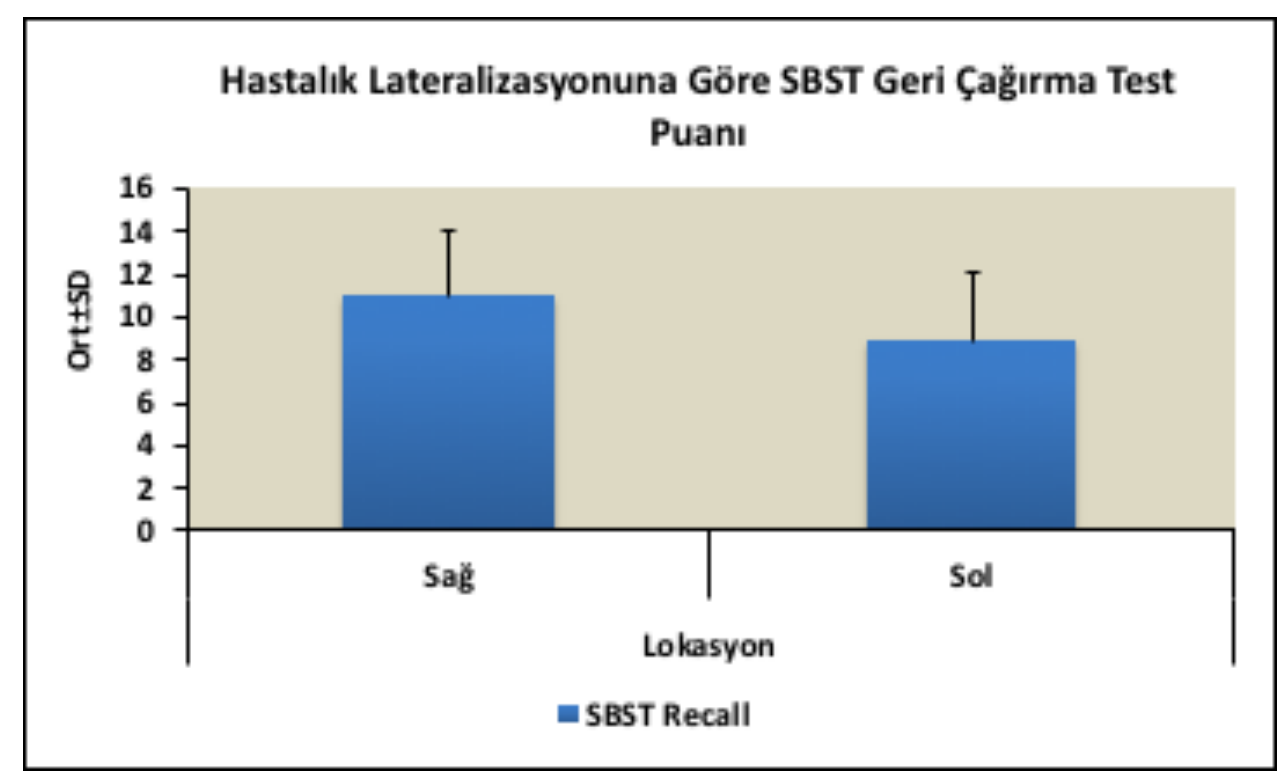

Şekil 1. Hastalık lateralizasyonuna göre SBST (Sözel Bellek Süreçleri Testi) geri çağırma test puanı. 
özgünlük teorisinin gözden geçirilmesi gerektiği sonucuna varmışlardır [14]. Bell ve ark.'nın yaptığı çalışmada ise bellek performanslarında global etkilenme olan hastalarda, lezyonla ilişkili olmayan, özellikle karşı taraftaki epileptik aktivitenin uzak etkileri nedeni ile iki yanlı hipokampal işlevsel bozukluğun bu duruma yol açmış olabileceği düşünülmüştür [15]. Delaney ve arkadaşlarının yaptığı bir diğer çalışmada ise; sağ HS'u olan olgularda görsel bellek, sol HS'u olan olgularda sözel bellek kusurları gösterilmiştir. Bazı MTLE olgularında tek taraflı lokalizasyon olmasına rağmen hem sözel hem de görsel bellek kusurlarının birlikteliği karşı temporal lobun da etkilendiğini düşündürmüş, ayrıca her iki temporal lobun etkilendiği ve özellikle bilateral temporal deşarjların izlendiği olgularda bellek kusurlarını çok daha belirgin bulmuşlardır [5]. Bexandale ve ark.'na göre ise hipokampal patoloji bellek problemlerinin ana kaynağı olmakla birlikte, sürekli epileptik aktivite olması, interiktal epileptik deşarj ve diğer epileptik klinik özelliklerin de bellek problemleri ile ilişkili olabileceği kanısına varmışlardır [16]. Mantıksal bellek değerlendirmesinde ise sağ ve sol HS'u olan hastaların kontrol grubuna göre anlamlı olarak düşük performans gösterdiğini ancak sağ ve sol HS'u olan hastalar arasında mantıksal bellek performansları açısından fark olmadığını saptadık. Aynı zamanda sözel bellek parametresi içerisinde de değerlendirilen mantıksal bellek testinde lateralizasyonla uyumlu bellek bozukluğu saptamamamı, mantıksal belleğin lateralizasyon değerinin az olduğunu düşündürmüştür. Ayrıca hem sağ hem de sol HS'u olan hastalarda mantıksal bellek bozukluğu saptamamız ise, mantıksal bellekte her iki temporal lobun da etkisi olduğunu düşündürmüştür. Bu bulgular bu konuda yapılan bazı çalışmaları destelemektedir. Halmsteadter ve ark., sözel bellek kelime listesi öğrenme testinin mantıksal bellek testine göre lateralize epileptik patolojileri saptamada daha fazla duyarlıı̆ga sahip olduğunu bulmuşlardır [7]. Yine Salling ve ark. ise sözel bellekle ilişkili testlerden özellikle mantıksal bellek paradigmasında semantik özelliklerin oldukça belirgin olduğunu ve bu nedenle mantıksal belleği hem meziyal temporal ve lateral neokortikal yapılar, hem de her iki temporal lob ile ilişkili bulmuşlardır [17]. MTLE'li hastaların bir kısmında nöropsikometrik değerlendirmelerde, bellek testlerinin yanısıra frontal işlevlerde ve bazen vizyospasyal işlevlerde düşük performans izlenmektedir. Bu bulguların anlamı bugün için çok açık olmasa da temporal ve prefrontal alanlar arasındaki yoğun etkileşim nedeniyle, özellikle sekonder jeneralizasyon ile frontal lob işlevlerinin bozulabileceği düşünülmüştür [2].

Çalışmamızda hem sağ hem sol HS'lu hastalar dikkat ve diğer yürütücü işlevler açısından, kontrol grubuna göre karşılaştırıldığında; bu testlerde anlamlı düzeyde düşük performans göstermişlerdir. Sağ ve sol HS'lu hastalar arasında ise dikkat ve diğer yürütücü işlevler açısından anlamlı fark saptanmamıştır. Bu sonuçlar bize dikkat ve diğer yürütücü işlevlerde bozulmanın hastalık lateralizasyonu ile ilişkisi olmadığını düşündürtmüştür. Literatürleri incelediğimizde yürütücü işlevlerin lateralizasyonla ilişkisi tartışmalıdır. Bu konuda yapılan bazı çalışmalar bizim bulgularımızı destekler nitelikte sonuçlara ulaşmışlar ve yürütücü işlevlerin hastalık lateralizasyonu ile ilişkisini saptamamışlardır $[18,19]$. Giovagnoli ve ark. ise sol HS'u olan hastaların sağ HS'u olan hastalara göre yürütücü işlevlerde daha düşük performans gösterdiğini saptamışken [20], Corcoran ve ark. ile Upton ve ark. tam tersini savunmuşlardır [21, 22]. Zamarian ve ark.'nın yaptığı çalışmada ise 28 MTLE hastasına kapsamlı bir yürütücü işlev test bataryası uygulanmış ve sadece verbal akıcılık testinde sol HS'lu hastalarda sağa göre daha fazla performans düşüklüğü saptanmış, diğer testlerde lateralizasyon bulgusu saptanmamıştır. Ayrıca hem sol hem de sağ HS'lu hastalarda kontrol grubuna göre yürütücü işlevlerde bozukluk saptamışlardır [23].

Sonuç olarak, bu çalışmada literatürle uyumlu olarak sol HS'u olan hastalarda sözel bellekte etkilenme olduğu ancak sağ HS'u olan hastalarda görsel bellekte etkilenme olmadığını saptadık. Ayrıca literatürdeki bazı çalışmalara benzer şekilde dikkat ve diğer yürütücü işlevlerin de lateralizasyon değerinin olmadığını tespit ettik. Gelecekte daha fazla hasta sayısıyla lateralizasyon ve frontostriatal ağdaki değişimlerin ilişkisini gösteren fonksiyonel görüntüleme çalışmalarıyla bu durum netlik kazanabilir [24].

Çıkar İlişkisi: Yazarlar çıkar ilişkisi olmadığını beyan eder. 


\section{Kaynaklar}

1- Kneebone AC. Presurgical Neuropsychological Evaluation for Localization of the Epileptogenic Zone. Epilepsy Surgery.2.ed. Philadelphia:Lippincott Williams\&Wilkins 2001;487-946.

2- Jokeit H, Seitz RJ, Markowitsch HJ, Neumann N, Witte OW, Ebner A. Prefrontal asymmetric interictal glucose hypometabolism and cognitive impairment in patients with temporal lobe epilepsy. Brain 1997;120:22832294. https://dx.doi.org/10.1093/brain/120.12.2283

3- Özkara Ç, Bora I, Yeni SN, ve ark. Temporal Lob Epilepsileri 1. basım, İstanbul, Nobel Tıp Kitabevleri 2008;301-317.

4- Sencer S, Kınay D, Gürses C, et al. Cerrahi uygulanan mezial temporal skleroz olgularında klinik ve MRG bulgular. Tanısal ve Girişimsel Radyoloji 2003;9:171175.

5- Delaney RC, Rosen AJ, Mattson RH, Novelly RA. Memory function in focal epilepsy: a comparison of non-surgical, unilateral temporal lobe and frontal lobe samples. Cortex 1980;16:103-117.

6- Helmstaedter C, Wietzke J, Lutz MT. Unique and shared validity of the "Wechsler logical memory test", the "California verbal learning test", and the "verbal learning and memory test" in patients with epilepsy. Epilepsy Res 2009;87:203-212. https://dx.doi.org/10.1016/j. eplepsyres.2009.09.002

7- Helmstaedter C, Elger CE. Chronic temporal lobe epilepsy: a neurodevelopmental or progressively dementing disease? Brain 2009;132:2822-2830. https://dx.doi.org/10.1093/brain/awp182

8- Helmstaedter C, Kurthen M, Lux S, Reuber M, Elger CE. Chronic epilepsy and cognition: a longitudinal study in temporal lobe epilepsy. Ann Neurol 2003;54:425-432. https://dx.doi.org/10.1002/ana.10692

9- Baxendale SA, van Paesschen W, Thompson PJ, et al. The relationship between quantitative MRI and neuropsychological functioning in temporal lobe epilepsy. Epilepsia 1998;39:158-166. https://dx.doi. org/10.1111/j.1528-1157.1998.tb01353.x

10- Jokeit $\mathrm{H}$, Ebner A. Long term effects of refractory temporal lobe epilepsy on cognitive abilities: a cross sectional study. J Neurol Neurosurg Psychiatry 1999;67:44-50.

11- Sass KJ, Buchanan CP, Kraemer S, Westerveld M, Kim $\mathrm{JH}$, Spencer DD. Verbal memory impairment resulting from hippocampal neuron loss among epileptic patients with structural lesions. Neurology 1995;45:2154-2158. https://doi.org/10.1212/WNL.45.12.2154

12- Wagner DD, Sziklas V, Garver KE, Jones-Gotman M. Material-specific lateralization of working memory in the medial temporal lobe. Neuropsychologia 2009;47:112-122. https://dx.doi.org/10.1016/j. neuropsychologia.2008.08.010
13- Glikmann-Johnston Y, Saling MM, Chen J, Cooper KA, Beare RJ, Reutens DC. Structural and functional correlates of unilateral mesial temporal lobe spatial memory impairment. Brain 2008;131:3006-3018. https://dx.doi.org/10.1093/brain/awn213

14- Hanoğlu L, Şengül HS, Erbayat E, et al. Temporal lob epilepside lateralize edici bulgu olarak materyal spesifik bellek bozukluğu. Epilepsi 2014;20:67-74. https://dx.doi.org/10.5505/epilepsi.2014.96967

15- Bell B, Lin JJ, Seidenberg M, Hermann B. The neurobiology of cognitive disorders in temporal lobe epilepsy. Nat Rev Neurol 2011;7:154-164. https:// dx.doi.org/10.1038/nrneurol.2011.3

16- Baxendale SA, Van Paesschen W, Thompson PJ, Duncan JS, Harkness WF, Shorvon SD. Hippocampal cell loss and gliosis: relationship to preoperative and postoperative memory function. Neuropsychiatry Neuropsychol Behav Neurol 1998;11:12-21.

17- Saling MM, Wilson SJ. Presurgical diagnostics. In: Helmstaedter C, Hermann B, Lassonde M, Kahane P, Arzimanoglou A, editors. Neuropsychology in the care of people with epilepsy. Montrouge, France: John Libbey Eurotext 2011;191-199.

18- Tudesco Ide S, Vaz LJ, Mantoan MA, et al. Assessment of working memory in patients with mesial temporal lobe epilepsy associated with unilateral hippocampal sclerosis. Epilepsy Behav 2010;18:223-238. https:// dx.doi.org/10.1016/j.yebeh.2010.04.021

19- Black LC, Schefft BK, Howe SR, Szaflarski JP, Yeh HS, Privitera MD. The effect of seizures on working memory and executive functioning performance. Epilepsy Behav 2010;17:412-419. https://dx.doi.org/10.1016/j. yebeh.2010.01.006

20- Giovagnoli AR. Relation of sorting impairment to hippocampal damage in temporal lobe epilepsy. Neuropsychologia 2001;39:140-150.

21- Corcoran R, Upton D. A role for the hippocampus in card sorting? Cortex 1993;29:293-304.

22- Upton $\mathrm{D}$, Corcoran $\mathrm{R}$. The role of the right temporal lobe in card sorting: a case study. Cortex 1995;31:405-409.

23- Zamarian L, Trinka E, Bonatti E, et al. Executive functions in chronic mesial temporal lobe epilepsy. Epilepsy Res Treat 2011;2011:596174. https://dx.doi. org/10.1155/2011/596174

24- Riley JD, Moore S, Cramer SC, Lin JJ. Caudate atrophy and impaired frontostriatal connections are linked to executive dysfunction in temporal lobe epilepsy. Epilepsy Behav 2011;21:80-87. https://dx.doi. org/10.1016/j.yebeh.2011.03.013

Yazarlar Sayın Doç. Dr. Dilek Ataklı'ya katkılarından dolayı teşekkür eder.

Bu çalışmamızda, S.B.Ü Bakırköy Prof. Dr.Mazhar Osman Ruh Sağlığı ve Sinir Hastalıkları Eğitim ve Araştırma Hastanesi Etik 
Kurulu'ndan 03.06.2014 tarih ve 402 no ile Etik Kurul onayı alan "Mezial Temporal Lob Epilepsisi Tanısı Alan ve İlaç Tedavisine İyi Yanıtı Hastalar ile İlaç Tedavisine Dirençli Hastaların Bellek ve Dikkat Testlerinin Karşılaştırılması" başlıklı tez çalışması için toplanan ancak tezde kullanılmayan alt grup analizleri kullanılmış olup, aynı kuruldan verilerin kullanılması için 06.11.2018 tarihinde etik kurul onayı alınmıştır. 